\title{
Diagnostic and therapeutic efficacy of barium meal examination: a prospective evaluation in general practice
}

\author{
B G Conry, A M McLean, M J G Farthing
}

\begin{abstract}
Objective-To assess the efficacy of barium meal examinations in managing patients with dyspepsia in general practice.

Design-Prospective study by questionnaires completed by general practitioners before and within three to six months after the barium meal examination. Information was requested about the patients' symptoms, current treatment, reason for requesting the examination, and the working diagnosis, including degree of certainty and, after the examination, about any change in diagnosis, diagnostic confidence, or management and to determine whether the examination was judged to be helpful or not.

Setting - Inner city health district.

Patients - 133 Patients with dyspepsia referred by general practitioners for outpatient barium meal examination, 31 of whom failed to attend for the examination, or refused it on arrival, or did not have fully completed questionnaires. Two patients were not available for follow up.
\end{abstract}

Main outcome measures-Prevalence of radiological abnormalities and the influence of the examination result on management, particularly changes in drug treatment.

Results-Fully completed pairs of questionnaires were available for 100 patients, 58 of whom were aged below 50 . Most of the barium meal reports (64) were to confirm the clinical diagnosis; only 22 were to exclude serious disease. Ninety nine patients were already receiving treatment, with 39 taking an $\mathbf{H}_{2}$ receptor antagonist. Fifty eight barium meal examinations showed abnormalities (31 major abnormalities); there were no cancers and in only 18 patients was the working diagnosis changed as a result of the findings. Although the barium meal result increased management confidence (63 patients) and allayed patients' anxiety (46), changes in management attributed directly to the examination occurred in only 22 patients. Management changes were minor, usually comprising interchange of antacids and $\mathrm{H}_{2}$ receptor antagonists.

Conclusions-Young patients (aged below 50) with dyspepsia are still being overinvestigated. Although barium meal examination improves diagnostic confidence and allays patients' anxiety, fully utilising communication skills at the initial consultation might allay anxiety more economically.

Departments of Radiology and Gastroenterology, St Bartholomew's Hospital, London EC1A 7BE B G Conry, FRCR, senior registrar in radiology A M McLean, FRCR, consultant radiologist

M J G Farthing, FRCP, reader in gastroenterology

Correspondence to: $\mathrm{Dr}$ Farthing.

BrMed f 1989;299:1443-5

\section{Introduction}

The prevalence of dyspepsia in the United Kingdom remains high. Although most patients do not seek medical advice, a recent community survey of more than 2000 patients indicated that up to tenth had consulted their general practitioner for symptoms of dyspepsia over six months; a fifth of these had been investigated with a barium meal examination sometime in the past.

Despite the increasing availability of endoscopy and widespread use of $\mathrm{H}_{2}$ receptor antagonists barium meal examination remains popular, accounting for over $17 \%$ of all general practitioner requests for $x$ ray examinations in hospitals and second only in frequency to requests for chest $x$ ray examinations. ${ }^{2}$ The need to investigate young patients with uncomplicated dyspepsia has been questioned, ${ }^{34}$ such that many now consider that empirical treatment of the symptoms with $\mathrm{H}_{2}$ receptor antagonists may suffice, leaving only a small group of non-responders who require investigation.

The workload of many radiology departments is changing, and increasing demand on resources requires continued evaluation of the efficacy of familiar diagnostic tests. A critical appraisal of the usefulness of a diagnostic test requires evaluation of its impact on diagnosis, management, and patient outcome. Many studies consider only the value of a positive result, but a negative result may be equally valuable, by its effect in changing the range of diagnostic possibilities ${ }^{5}$ and by virtue of its reassurance value.

We carried out a prospective study of the efficacy of barium meal examinations in general practice to determine the impact of the test result on management and patient outcome.

\section{Patients and methods}

All patients with dyspepsia referred for a barium meal examination by general practitioners in the City and Hackney Health District were eligible for the study, and 133 consecutive patients referred by 40 general practitioners were enrolled. After the request for the examination had been accepted the general practitioners were invited to complete an initial questionnaire during a maximum of three weeks before the examination, giving details of the patients' symptoms, history, and main working diagnosis, and their own degree of certainty about the diagnosis. They were asked about the nature and duration of any treatment and the main reason for requesting the examination: specifically to confirm or exclude disease, to reassure the patient, or as a result of direct pressure from the patient.

A second questionnaire, completed by the general practitioners between three and six months after the examination inquired about any change in diagnosis, diagnostic confidence, or management and how helpful or otherwise the examination had been. The general practitioners were not given a copy of their initial responses when they completed the second questionnaire. The results in the examination report were classified as normal, abnormal, or equivocal. Abnormal results were subdivided into major and minor abnormalities; major abnormalities were assessed as those probably requiring specific medical treatment (for example, ulcer, reflux oesophagitis, and erosions) or surgical or endoscopic intervention (for example, suspicion of cancer, stricture, etc) and minor abnormalities as incidental findings (for example, uncomplicated small hiatus hernia and minor oesophageal motility disorder). The examinations were performed in all patients by the double contrast technique with routine use of smooth muscle relaxants by registrars 
$(71 \%)$, senior registrars $(20 \%)$, and consultants (9\%). All examinations performed by registrars were reviewed by a consultant or senior registrar before a report was issued.

\section{Results}

At the end of the study 100 fully completed pairs of questionnaires were available for analysis. Of the 133 patients recruited, 10 failed to attend for their examination, one refused the examination on arrival, 21 did not fully complete their questionnaire or did not return it, and two were not available for follow up. The final study group consisted of 57 men and 43 women, $58 \%$ of whom were aged under 50 and 24 under 30 .

Most (64) of the 100 referrals for a barium meal examination were made to confirm the clinical diagnosis and in 21 the stated reason was to exclude serious disease; reassurance of the patient accounted for 11 and direct patient pressure for four. All but one patient attending for an examination were taking some form of treatment; 39 were taking $\mathrm{H}_{2}$ receptor antagonists, and the remainder were taking antacids or other treatment, with 22 taking more than one drug. In a quarter of patients the symptoms had already improved at the time the examination was requested. Eight patients gave a history of previously proved peptic ulceration.

Tables I and II show the findings on barium meal examination; 58 of the examinations showed abnormalities. The proportions of abnormalities requiring treatment were the same in patients aged under 50 $(31 \%)$ and over $50(33 \%)$. No patient was found to have either gastric or oesophageal cancer, although one who had normal barium meal findings was subsequently found to have a para-aortic node mass consisting of high grade lymphoma.

Table III compares the working diagnosis before and after the examination; in 64 cases the working diagnosis was confirmed and in 18 it was changed. In the remaining 18 a specific answer was not provided, possibly because the general practitioners could not recall their initial stated diagnosis. In 17 the final diagnosis stated by the general practitioners disagreed with the result of the examination (table IV).

Although in most patients the diagnosis before the examination was unchanged, clinical confidence in the diagnosis increased after the examination (diagnostic certainty or near certainty in 63 patients after examination $v 18$ patients before examination; table V). Changes in management occurred in 40 patients after

TABLE I-Barium meal findings in 100 patients with dyspepsia. Figures are numbers (percentages)

\begin{tabular}{lrlccc}
\hline & & Normal & Major abnormality & Minor abnormality & Equivocal \\
\hline Total & 100 & 41 & 31 & 27 & 1 \\
$\quad \begin{array}{l}\text { Patients aged }>50 \\
\begin{array}{c}\text { Patients aged } \leqslant 50 \\
\text { Patients taking H }\end{array} \\
\begin{array}{c}\text { receptor antagonists } \\
\hline\end{array}\end{array}$ & 52 & $12(29)$ & $13(31)$ & $17(40)$ & $1(2)$ \\
\hline
\end{tabular}

TABLE II - Abnormalities detected on barium meal examination in 100 patients with dyspepsia

\begin{tabular}{lc}
\hline Diagnosis & No of patients \\
\hline Major abnormalities & 31 \\
Duodenal scarring & 13 \\
Duodenal ulcer & 8 \\
Gastric ulcer & 3 \\
Duodenitis & 2 \\
Gastritis & 2 \\
Gastric erosions & 2 \\
Oesophagitis & 1 \\
Minor abnormalities & 27 \\
Hiatus hernia and reflux & 12 \\
Gastro-oesophageal reflux & 9 \\
Hiatus hernia & 3 \\
Tertiary oesophageal contractions & 1 \\
Epiphrenic diverticulum & 1 \\
\end{tabular}

TABLE III - Working diagnosis before and after barium meal examination in 100 patients

No of patients

\begin{tabular}{lcc}
\hline & \multicolumn{2}{c}{ No of patients } \\
\cline { 2 - 3 } Diagnosis & Before examination & After examination \\
\hline Normal & 18 & 35 \\
Gastric ulcer & 12 & 6 \\
Duodenal ulcer & 43 & 24 \\
Erosions & 3 & 5 \\
Hiatus hernia & 24 & 25 \\
Other & & 5 \\
\hline
\end{tabular}

TABLE IV-Final working diagnoses of general practitioners that disagreed with diagnoses after barium meal examination (17 patients)

\begin{tabular}{llll}
\hline $\begin{array}{l}\text { Diagnosis after } \\
\text { barium meal }\end{array}$ & No & $\begin{array}{l}\text { Final general } \\
\text { practitioner diagnosis }\end{array}$ & No \\
\hline Normal & $11\left\{\begin{array}{l}\text { Duodenal ulcer } \\
\text { Gastric ulcer } \\
\text { Gastritis }\end{array}\right.$ & 3 \\
Erosions & 2 \\
Reflux & 2 \\
Hiatus hernia & 1 \\
Duodenal scarring & 1 & Normal & 2 \\
Gastric erosions & 1 & Duodenal ulcer & 1 \\
Hiatus hernia and reflux & 1 & Duodenal ulcer & 1 \\
Hiatus hernia & Normal & 1 \\
Gastro-oesophageal reflux & 1 & Duodenal ulcer & 1 \\
Tertiary oesophageal contractions & 1 & Normal & 1 \\
\hline
\end{tabular}

TABLE $\mathrm{v}-$ Degree of certainty of diagnosis before and after barium meal examination in 100 patients

\begin{tabular}{lcc}
\hline & \multicolumn{2}{c}{ No of patients } \\
\cline { 2 - 3 } & Before examination & After examination \\
\hline Possible & 36 & 17 \\
Probable & 46 & 20 \\
Almost certain & 16 & 36 \\
Certain & 2 & 27 \\
\hline
\end{tabular}

the examination; in 22 this was a direct result of the findings whereas in 18 this was not acknowledged as such by the general practitioner. In 14 patients treatment was stopped and in 23 antacids and $\mathrm{H}_{2}$ receptor antagonists were interchanged. Five patients with normal findings on examination continued to be treated with $\mathrm{H}_{2}$ receptor antagonists. Confidence in the initial management was increased in 45 patients. In five patients the result precipitated referral for endoscopy; two required investigation of gastric ulcers, two clarification of a nodular appearance of the duodenum, and one clarification of an equivocal report. In 46 patients anxiety was reported to have been allayed as a result of the examination; 16 patients failed to attend for follow up within three months after the examination. Overall, the general practitioners thought that the examination was helpful in 76 patients; in five patients, in whom the results were equivocal or disagreed with the clinical impression or the importance of the disclosure of a scarred duodenal cap was not appreciated, the examination was deemed to be unhelpful.

\section{Discussion}

The efficacy of a diagnostic test needs to be assessed at several levels. Its immediate effect is clearly on the clinician's diagnosis, but beyond that the information influences decisions about treatment. Ultimately, the test will influence the patient's outcome, which may be more complex than relief of presenting symptoms and include reassurance and satisfaction that diagnosis and morbidity have been established from the tests. ${ }^{6}$

For a diagnostic test to have any appreciable clinical effect it must be accurate. Although less sensitive than endoscopy in detecting superficial mucosal erosions, the results of a double contrast barium meal examination performed by an experienced radiologist compare 
favourably with those of endoscopy in detecting peptic ulcer disease and oesophageal and gastric malignancy and in assessing hiatus hernia, gastro-oesophageal reflux, and oesophagitis. ' Barium meal examination remains an effective and popular outpatient investigation for dyspepsia, with good patient acceptability and low morbidity.

The rate of abnormality of $58 \%$ in this study suggests a high diagnostic yield, although in only 31 patients $(31 \%)$ was the abnormality relevant to their symptoms, thus warranting specific treatment. The rate of clinically significant abnormality was higher than that reported for chest $x$ rays requested by general practitioners, which disclosed a relevant abnormality in $21 \% .{ }^{8}$ In most of our patients, however, their condition was diagnosed clinically before the barium meal examination and the main influence of the examination was to confirm the original diagnosis and reassure the clinician that the proposed management was appropriate.

Surprisingly, most referred patients (58) were aged under 50, and the detection rate of significant abnormalities was almost identical with that of the over 50 age group, which conflicts with previous data. ${ }^{4}$ No gastrointestinal malignancy was detected in either group, although in $22 \%$ of patients the exclusion of a serious condition, usually cancer, was the main reason stated for requesting the examination. There is considerable evidence that the investigation of dyspepsia in young patients (aged under 50) is rarely rewarding in terms of management. ${ }^{349}$ The incidence of malignancy is low in this group, and such patients usually present with additional symptoms of anorexia and weight loss. ${ }^{10}$ There may be several reasons why requests for barium meal examination continue for young patients. Standard clinical teaching dictates that a diagnosis is required before starting treatment with expensive drugs. The fact that 15 examinations were performed simply for reassurance or as a result of direct pressure from patients reflects the difficulty with empirical management, particularly in patients with recurrent dyspepsia. The therapeutic effect of normal findings on examination may be substantial in many patients, and in almost half the group studied patients' anxiety was allayed by the examination. Such reassurance may have been a factor for failure of 16 patients to consult the general practitioner after the examination.

The change in management of $40 \%$ was considerably higher than the $11 \%$ reported in young dyspeptic patients ${ }^{4}$ and compares favourably with the other commonly used tests. A study of the influence of barium enema examination for a wide range of presenting symptoms indicated that it excluded serious conditions in $64 \%$ of patients and changed management in $24 \% .{ }^{11}$ In another study the plain abdominal film changed management in $10 \%$ of acute surgical admissions. ${ }^{12}$ In most of our patients, however, the management changes entailed fairly minor manipulations, usually interchange of $\mathrm{H}_{2}$ receptor antagonists and antacids. As all but one patient were receiving the same form of treatment at the time of the examination the main influence was that of stopping treatment; all treatments were withdrawn in 14 patients and $\mathrm{H}_{2}$ receptor antagonists were withdrawn in eight at the end of follow up.

Although the resultant management changes might seem unimportant, the examination was regarded as helpful in 76 patients. The main benefit seemed to be that of increasing the diagnostic and therapeutic confidence of the referring clinician and alleviating patient anxiety. As allocation of increasingly limited health care resources will probably be made in favour of tests with demonstrably high efficacy in diagnosis and management it is difficult to determine what value should be placed on the reassurance of patients and clinicians. In some patients the examination probably prevented costly referral for outpatient consultation. As, however, in most patients the initial diagnosis and management was correct perhaps general practitioners should be more confident in their primary diagnosis and alleviate patients' anxiety by communicating their confidence. After an initial trial of treatment a few patients would doubtless remain who might then benefit from investigation.

Overall we conclude, in common with Williams $e$ $a l,{ }^{3}$ that young patients with simple dyspepsia are being overinvestigated and that the first step in management should be a trial of an antacid or $\mathrm{H}_{2}$ receptor antagonists. Our study shows that barium meal examination is valuable in this group for reassuring patients and clinicians but that an equally satisfactory outcome might be achieved by communicating fully at the initial consultation.

MJGF is a Wellcome Trust senior lecturer. The study was supported by a research grant from Smith, Kline and French Laboratories whose administrative support allowed it to be carried out. 1 Jones R, Lydeard S. Prevalence of symptoms of dyspepsia in the community.
Br Med f 1989;298:30-2.

2 Barton E, Gallagher S, Flower CDR, Hanka R, King RH, Sherwood T. Influence on patient management of general practitioner direct access to radiological services. BrF Radiol 1987;60:893-6.

3 Williams B, Luckas M, Ellingham JHM, Dain A, Wicks ACB. Do young patients with dyspepsia need investigation? Lancet 1988;ii:1349-51.

4 Mead GM, Morris A, Webster GK, Langman MJS. Uses of barium meal examination in dyspeptic patients under 50. Br Med f 1977;i:1460-1.

5 Gorry GA, Pauker SG, Schwartz WB. The diagnostic importance of the normal finding. N Eng f Med 1978;298:486-9.

6 Anonymous. Evaluating efficacy [Editorial]. American fournal of Roentgenology 1980;134:1277-9.

Guyer PB, Chalmers AG. Chest radiography for general practitioners - a low yield investigation. $7 R$ Coll Gen Pract 1983;33:477-9.

8 Gelfand DW, Ott DJ, Munitz HA, Chen YM. Radiology and endoscopy: radiologic viewpoint. Ann Intern Med 1984;101:550-2.

9 Marton KI, Sox HC, Wasson J, Duisenburg CE. The clinical value of the upper gastrointestinal tract roentgenogram series. Arch Intern Med 1980 upper gastrin

10 Davenport PM, Morgan AG, Darnborough A, De Dombal FT. Can preliminary screening of dyspeptic patients allow more effective use of investigation techniques? Br Med f 1985;290:217-20.

11 Chen YM, Ott DJ, Gelfand DW, Munitz HA. Impact of barium enema on patient management. Gastrointest Radiol 1988;13:81-4.

12 Hayward MW, Hayward C, Ennis WP, Roberts CJ. A pilot evaluation of radiography of the acute abdomen. Clin Radiol 1984;35:289-91.

(Accepted 21 September 1989)

\section{ANY QUESTIONS}

Some patients are taking fish oil and evening primrose oil for arthritis and aspirin as a preventive against vascular disorder. Is there any danger in taking these substances together?

Both fish oil and evening primrose oil affect platelet function by interfering with the production of thromboxane $\mathrm{A}_{2}$. Maxepa (fish oils) $50 \mathrm{ml}$ daily inhibits platelet function to a lesser degree than does aspirin $325 \mathrm{mg}$ daily. The size of the effect of evening primrose oil is uncertain but is unlikely to be greater than the effect of fish oils. Aspirin also inhibits platelet function through its effect on thromboxane $A_{2}$ synthesis, and the effect would probably be additive with those of fish oils and evening primrose oil.
So far as I am aware the effects of these combinations on platelet function have not been measured. The risk of bleeding, however, may be greater if the three substances are taken in combination; the effect of fish oils and evening primrose oil in combination may be greater than that of either alone-perhaps roughly equivalent to that of $325 \mathrm{mg}$ aspirin.LINDA BEELEY, consultant clinical pharmacologist, Birmingham

Knapp HR, Reilly IAG, Alessandrini P, Fitzgerald GA. In vivo indexes of platelet and vascular functions during fish-oil administration in patients with atherosclerosis. $N$ Engl $\mathcal{F}$ Med 1986;314:937-42.

Anonymous. Fish oil. Lancet 1988;i:1081-3.

Barber AJ. Evening primrose oil: a panacea? Pharmaceutical fournal 1988;240:723-5. 